\title{
Association between unmet medication needs after hospital discharge and readmission or death among acute respiratory failure survivors: the addressing post-intensive care syndrome (APICS-01) multicenter prospective cohort study
}

Samuel M. Brown ${ }^{1,2,3,11^{*}}$ (D) Victor D. Dinglas ${ }^{4}$, Narjes Akhlaghi ${ }^{5}$, Somnath Bose ${ }^{6}$, Valerie Banner-Goodspeed ${ }^{6}$, Sarah Beesley 1,2,3, Danielle Groat 1,3, Tom Greene7, Ramona O. Hopkins 3,8, Mustafa Mir-Kasimov' 2,9, Carla M. Sevin ${ }^{10}$, Alison E. Turnbull ${ }^{4}$, James C. Jackson ${ }^{10}$, Dale M. Needham ${ }^{4}$ and for the APICS-01 Study Team

\begin{abstract}
Introduction: Survivors of acute respiratory failure (ARF) commonly experience long-lasting physical, cognitive, and/ or mental health impairments. Unmet medication needs occurring immediately after hospital discharge may have an important effect on subsequent recovery.

Methods and analysis: In this multicenter prospective cohort study, we enrolled ARF survivors who were discharged directly home from their acute care hospitalization. The primary exposure was unmet medication needs. The primary outcome was hospital readmission or death within 3 months after discharge. We performed a propensity score analysis, using inverse probability weighting for the primary exposure, to evaluate the exposure-outcome association, with an a priori sample size of 200 ARF survivors.

Results: We enrolled 200 ARF survivors, of whom 107 (53\%) were female and 77 (39\%) were people of color. Median (IQR) age was 55 (43-66) years, APACHE II score 20 (15-26) points, and hospital length of stay 14 (9-21) days. Of the 200 participants, 195 (98\%) were in the analytic cohort. One hundred fourteen (57\%) patients had at least one unmet medication need; the proportion of medication needs that were unmet was 6\% (0-15\%). Fifty-six (29\%) patients were readmitted or died by 3 months; 10 (5\%) died within 3 months. Unmet needs were not associated (risk ratio 1.25; 95\% $\mathrm{Cl}$ 0.75-2.1) with hospital readmission or death, although a higher proportion of unmet needs may have been associated with increased hospital readmission (risk ratio 1.7; $95 \% \mathrm{Cl} 0.96-3.1$ ) and decreased mortality (risk ratio $0.13 ; 95 \%$ $\mathrm{Cl}$ 0.02-0.99).
\end{abstract}

*Correspondence: Samuel.Brown@imail.org

${ }^{11}$ Shock Trauma ICU, Intermountain Medical Center, 5121 S. Cottonwood Street, Murray, UT 84107, USA

Full list of author information is available at the end of the article

(c) The Author(s) 2021. Open Access This article is licensed under a Creative Commons Attribution 4.0 International License, which permits use, sharing, adaptation, distribution and reproduction in any medium or format, as long as you give appropriate credit to the original author(s) and the source, provide a link to the Creative Commons licence, and indicate if changes were made. The images or other third party material in this article are included in the article's Creative Commons licence, unless indicated otherwise in a credit line to the material. If material is not included in the article's Creative Commons licence and your intended use is not permitted by statutory regulation or exceeds the permitted use, you will need to obtain permission directly from the copyright holder. To view a copy of this licence, visit http://creativecommons.org/licenses/by/4.0/. The Creative Commons Public Domain Dedication waiver (http://creativeco mmons.org/publicdomain/zero/1.0/) applies to the data made available in this article, unless otherwise stated in a credit line to the data. 
Discussion: Unmet medication needs are common among survivors of acute respiratory failure shortly after discharge home. The association of unmet medication needs with 3-month readmission and mortality is complex and requires additional investigation to inform clinical trials of interventions to reduce unmet medication needs.

Study registration number: NCT03738774. The study was prospectively registered before enrollment of the first patient.

Keywords: Acute respiratory failure, Long-term outcomes, Discharge planning, Health services research

\section{Introduction}

Post-discharge survival for patients with acute respiratory failure (ARF) is increasing [1-5]. Survivors often suffer from long-lasting impairments in physical, cognitive, and/or mental health status, and face substantial financial burden due to delayed return to work and associated loss of earnings, healthcare costs, and changes in insurance [6-20]. Survivors often experience fragmented healthcare after hospital discharge and mismatches between the healthcare services needed and those received during the vulnerable weeks immediately after discharge [21]. The immediate post-discharge period may be a time of particular vulnerability, with a potential outsize impact on subsequent recovery. Readmissions are common, expensive, and potentially avoidable [22-24]. Retrospective cohorts based on claims data have suggested that failures to follow through may be associated with early readmissions [25-27]. Similar to post-discharge management of heart failure [28], medications represent a particularly important target in the post-discharge care of patients who have survived an ICU admission [29-32]. Limited prospective data exist to clarify the relationships among support and care early after hospital discharge and subsequent clinical outcomes. We thus undertook a multicenter prospective cohort study to explore the associations of unmet medication needs after hospital discharge and hospital readmission or death 3 months after discharge among survivors of acute respiratory failure who were discharged directly to home. Early results have been published in abstract form [33, 34]. We have previously reported the underlying rationale for the study [35].

\section{Methods and analysis Study design}

This is a prospective multicenter cohort study of ARF survivors conducted at six hospitals affiliated with five US medical centers. We have published the methods in detail previously [36]; we summarize them here, with the full study protocol and statistical analysis plan provided in the Online Supplement. This paper reports our analysis of unmet medication needs, as distinct from other types of healthcare needs, which will be analyzed and reported subsequently.

\section{Patients}

We enrolled patients with ARF who were being discharged to home directly from the acute care hospital. We defined ARF as $\geq 24$ consecutive hours of (1) mechanical ventilation via an endotracheal tube, (2) noninvasive ventilation, or (3) high-flow nasal cannula with $\mathrm{FIO}_{2} \geq 0.5$ and flow rate $\geq 30 \mathrm{~L} / \mathrm{min}$. We excluded patients whose respiratory support was provided for reasons other than respiratory failure (e.g., airway obstruction or coma), for whom telephone-based follow-up was not feasible, or with preexisting dementia. Dementia was defined using Informant Questionnaire on Cognitive Decline in the Elderly (IQ-CODE) [37] screening, as commonly used in other ARF follow-up studies [13, 38].

\section{Primary exposure}

Unmet medication needs were the primary exposure of interest, assessed as soon as possible within a time window of 7-28 days after hospital discharge. Unmet medication needs were measured using a subset of a larger instrument we developed. Details of this larger instrument are provided in the online supplemental methods and have been published previously [36]. In this report, we focus on medication-related needs given the immediate relevance of medication needs (as opposed to nonmedication interventions that may not be scheduled until after initial follow-up has been completed).

Immediately after discharge, the medication needs instrument was completed. The initial telephone call to ascertain the primary exposure (unmet medication needs) was performed after a grace period of 7 days (to allow time for medical needs to be met), with the time window extending for up to 21 additional days. During the initial call, the medication needs instrument was used to identify and categorize each discharge need as completed or not completed based on changes in medication prescriptions (whether to start a new medicine, stop an established medicine, or change a medication dose). In other words, the total number of medication instructions/orders was the denominator. The numerator was the number of times an instruction was not implemented in the early post-discharge period. Thus, an unmet need might be, e.g., failure to start a new medication or failure to stop a medication that had been discontinued. The prespecified primary exposure variable was the 
proportion of medication needs that were unmet (e.g., if a patient had 8 needs and 2 were not met, the proportion unmet would be $25 \%$ ). For purposes of analysis, this proportion was treated as above versus below the median proportion for the overall cohort.

\section{Primary outcome}

The prespecified primary outcome was a composite binary outcome of hospital readmission or death within 3 months of discharge to home from the index hospitalization.

\section{Secondary outcomes}

Secondary outcomes included the constituent elements of the composite primary outcome as well as additional outcomes measured during 3- and 6-month centralized telephone-based follow-up assessments, including: at 3 months: cognitive impairment, depression, anxiety, post-traumatic stress disorder-related symptoms, emergency department visits and other healthcare utilization, and at 6 months: mortality, healthcare utilization, healthrelated quality of life, and return to work. This assessment included the recommended Core Outcome Set (COS) and associated measurement instruments for ARF survivors (see www.ImproveLTO.com) $[39,40]$. The centralized follow-up process followed established practices for optimizing participant retention [41-45].

\section{Statistical analysis}

Full details of the analysis are presented in the Statistical Analysis Plan provided in the Online Supplement. The primary analyses were specified before review of any data. The primary research question was whether unmet medication needs shortly after hospital discharge to home are associated with readmission or death within 3 months of hospital discharge in ARF survivors. The ultimate inferential target was whether meeting medication needs in the early post-discharge period will decrease hospital readmission or death. The primary analysis compared patients with an above-median proportion of unmet medication needs to patients with a below-median proportion of unmet medication needs.

Key methodological considerations for evaluating the association of the primary exposure and outcome are the management of reverse causation (the disease process underlying readmission or death by 3 months is the reason why the medication needs are unmet) and confounding by indication (e.g., more complex discharge plans, with a higher risk for unmet needs, occur for patients at higher risk for death or readmission). We used covariate balancing propensity score (CBPS) [46] adjustment to estimate the average causal ("treatment") effects in the treated. Under the assumption of no residual confounding, the respective treatment effects are the average reduction in the risk of the primary outcome among patients with above-median levels of unmet medication needs if an intervention reduced their proportion of unmet needs to below the median. (This dichotomization was used to improve the stability of regression models.) Secondary analyses addressed the proportions of unmet needs as continuous rather than dichotomized variables.

Covariates for multivariable models included patient characteristics at baseline and hospital discharge, including demographics, tobacco and alcohol use, severity of illness measures, and hospital length of stay. Covariates were specified before data were reviewed. The primary outcome model included enrolling site, age, and sex, and number of post-discharge medication needs as prespecified covariates. After finalizing the propensity score model, we used Poisson regression to estimate the risk ratio comparing the risk of the primary outcome between the two groups (those with above- vs. below-median proportion of unmet medication needs).

\section{Sample size and power}

Assuming a post-discharge attrition rate of $24 \%$, enrollment of 200 patients would result in 152 patients in the analytic cohort. We anticipated that $35 \%$ of patients would die or be readmitted by 3 months [30, 47]. Using statistical simulation, we estimated $80 \%$ power with two-sided $\alpha=0.05$ to detect an increase in the risk of the composite outcome from $30 \%$ for those in the lower unmet needs category to $53 \%$ for those in higher unmet needs category.

\section{Ethical considerations}

This study was funded by the U.S. Department of Defense (grant \# W81XWH-18-1-0813) and was registered at ClinicalTrials.gov (NCT03738774) before enrollment of the first patient. The study received approval from, and was overseen by, the central Institutional Review Board (IRB) at Vanderbilt University with additional oversight by the Human Research Protections Office (HRPO) of the Department of Defense. According to local policy, the Veterans Affairs hospital site was overseen by its designated IRB at the University of Utah. The study was fully approved before enrollment of the first patient. Informed consent was obtained prospectively from all participants or their legally authorized representatives. 


\section{Results}

Patients

We enrolled patients from January 2019 to August 2020. Among 5728 patients meeting inclusion criteria, 820 met all eligibility criteria. The most common reason for exclusion was for patients not being discharged directly home. Two hundred patients were consented and enrolled in the study (Fig. 1). After one patient withdrew prior to study procedures, we achieved 98\% (196/199) follow-up for ascertainment of primary exposure; we ascertained the primary endpoint at 3 months in 183/195 (94\%) of eligible patients ( 4 additional patients withdrew) and identified the primary endpoint from medical record review in another 12 patients. The analytic cohort thus contained 195 patients in whom both the primary exposure and outcome were known.

Baseline characteristics of enrolled patients are presented in Table 1. Median age was 55 (IQR 43-66) years, 104 (53\%) were female, and 77 (39\%) were people of color. Median duration of ICU and hospital stay was 6 (IQR 4-10) and 14 (IQR 9-21) days, respectively (Additional file 1: Table S1). At hospital discharge, 50 (26\%) patients were oxygen dependent and 11 (6\%) dialysis dependent (Additional file 1: Table S2).

At hospital discharge to home, the median number of total medication needs (i.e., the denominator for calculating the proportion of unmet medication needs) per patient was 13 (IQR 9-19). Overall, 114 (58\%) patients had at least one unmet medication need; the median (IQR) proportion of medication needs that were unmet was $6 \%(0-15 \%)$. In Table 2, we display the differences in baseline characteristics between those above versus below the median proportion of unmet medication needs. Patients above (vs. below) the median number of unmet medication needs more commonly were nonHispanic White, transferred to the study hospital from a referring hospital, a current smoker, and had ARDS during the index hospitalization (Table 2). Adjustment for propensity for the primary exposure yielded good covariate balance (Additional file 1: Table S3 and Additional file 1: Fig. S1).

\section{Study outcomes}

Overall, within 3 months, 56 (29\%) patients died or were readmitted to hospital, with 10 (5\%) dead and 52 (27\%) readmitted. Median time to death or readmission was 14 (IQR 7-47) days (Table 3). Causes of death are presented in Additional file 1: Table S4. Kaplan-Meier curves for the overall cohort and for patients above vs. below the median proportion of unmet medication needs are shown in Fig. 2, Additional file 1: Figs. S2 and S3. At 3 months (Additional file 1: Table S5) the median (IQR) health utility from the EQ-5D-5L was 0.8 (0.7-1.0), with one quarter of patients meeting criteria for anxiety, one quarter meeting criteria for depression, and $11 \%$ had post-traumatic stress symptoms. One-third of patients had evidence for cognitive impairment. By 6-month follow-up (Additional file 1: Tables S6 and S7), 17 (9\%) patients had died.

\section{Primary analysis}

The primary regression analysis did not identify a statistically significant association (risk ratio 1.25, 0.75-2.1) between above (vs. below) median unmet medication needs and the primary endpoint-death or readmission within 3 months (Additional file 1: Table S8). Regression models of the constituent endpoints were also performed. The risk ratio for above (vs. below) median proportion of unmet medication needs for death was $0.13(0.02-0.99 ; p=0.05)$, while the risk ratio for readmission was $1.7(0.96-3.1 ; p=0.07)$ (Additional file 1 : Table S9). On sensitivity analyses, treating the proportion of unmet needs as a continuous variable yielded similar results (Additional file 1: Table S10), as did adjusting for time (after hospital discharge) to assessment of unmet medication needs (Additional file 1: Table S11). Dichotomizing the exposure into all medication needs met versus any medication need unmet yielded similar results, with $95 \%$ confidence intervals that clearly excluded unity (Additional file 1: Table S12).

The discordance in associations between unmet medication needs and the risks of mortality and of readmission was evaluated in exploratory analyses. For participants who died, key unmet medication needs were primarily related to mental health medications (antidepressants and anxiolytics), other prescription medications (narcotics, muscle relaxants), and new prescriptions for corticosteroids and anticoagulants. Two of 10 patients died from cancer, with the other causes of death among the other 8 decedents being heterogenous (Additional file 1: Table S4). The patients who died had longer hospital and ICU length of stay, greater baseline frailty, were more likely to be enrolled into a discharge navigator program, and to have higher numbers of medication needs (16 vs. 12 needs) at the time of hospital discharge.

\section{Discussion}

This multicenter prospective cohort study of survivors of ARF found that more than half of participants had unmet medication needs shortly after discharge. The relationship between these unmet medication needs and 3-month outcomes appears complex: propensityadjusted regression analysis found that having fewer unmet medication needs may have been associated with a higher risk of mortality and a lower risk of hospital 


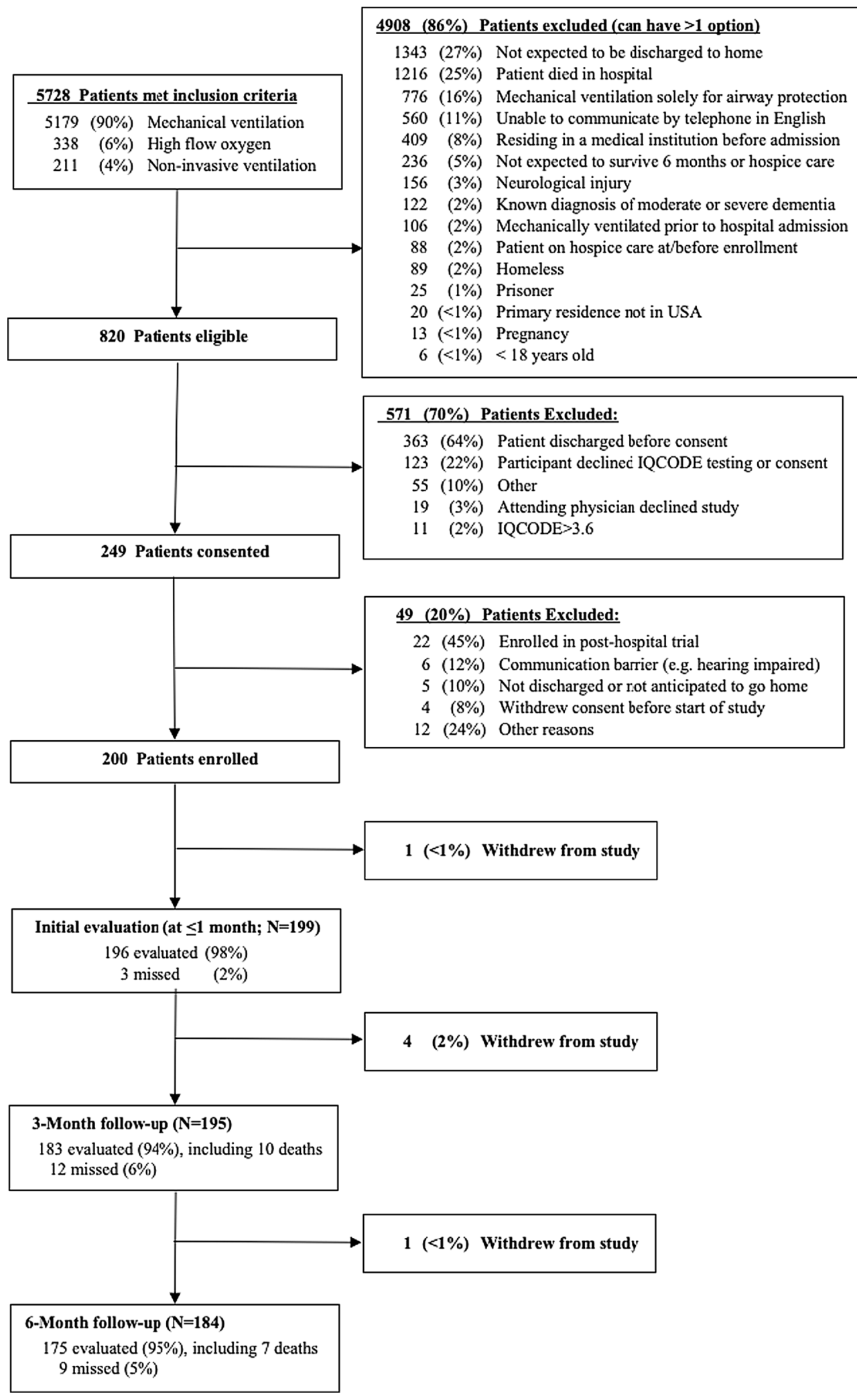

Fig. 1 Flow diagram of patient participation in APICS-01 
Table 1 Baseline characteristics of analyzed patients $(n=195)$

\begin{tabular}{|c|c|}
\hline Attribute & $\begin{array}{l}\text { Central } \\
\text { tendency } \\
\text { (dispersion) }\end{array}$ \\
\hline Age, years, median (IQR) & $55(43-66)$ \\
\hline Female sex, $n(\%)$ & $104(53.3 \%)$ \\
\hline \multicolumn{2}{|l|}{ Race, $n(\%)$} \\
\hline Black & $48(24.6 \%)$ \\
\hline Hispanic/Latinx & $5(2.6 \%)$ \\
\hline Non-Hispanic White & $129(66.2 \%)$ \\
\hline Other/multiple & $13(6.7 \%)$ \\
\hline Body mass index $\left(\mathrm{kg} / \mathrm{m}^{2}\right)$, median $(\mathrm{IQR})^{*}$ & $29.5(24.7-36.5)$ \\
\hline \multicolumn{2}{|l|}{ Respiratory support at enrollment, $n(\%)$} \\
\hline Invasive mechanical ventilation & $145(74.4 \%)$ \\
\hline Non-invasive mechanical ventilation & $13(6.7 \%)$ \\
\hline High-flow nasal cannula & $37(19.0 \%)$ \\
\hline Transferred from outside hospital, $n$ (\%) & 75 (38.5\%) \\
\hline APACHE II, score, median (IQR) & $20(15-26)$ \\
\hline Current smoker, $n(\%)$ & $31(15.9 \%)$ \\
\hline Acute respiratory distress syndrome, $n$ (\%) & $61(31.3 \%)$ \\
\hline Clinical frailty scale, median (IQR) & $3(2-4)$ \\
\hline Multidimensional scale perceived social support, median (IQR) & $72(60-81)$ \\
\hline Alcohol use disorders identification test (AUDIT), median (IQR) & $1(0-2)$ \\
\hline Abnormal AUDIT, $n(\%)$ & $16(8.2 \%)$ \\
\hline Functional capacity index, median (IQR) & $2(1-3)$ \\
\hline Charlson comorbidity index, median (IQR) & $1(0-3)$ \\
\hline Resides at home before admission & $190(97.4 \%)$ \\
\hline \multicolumn{2}{|l|}{ Employment status prior to admission $(n=161)$} \\
\hline Working (full/part-time), looking for work, or in school & $85(43.6 \%)$ \\
\hline Unemployed, not looking for work & $7(3.6 \%)$ \\
\hline Retired & $29(14.9 \%)$ \\
\hline Receiving disability payments & $32(16.4 \%)$ \\
\hline Prior COVID-19 hospitalization, $n$ (\%) & $0(0.0 \%)$ \\
\hline Tested positive for COVID-19 during admission, $n(\%)$ & $33(16.9 \%)$ \\
\hline
\end{tabular}

* BMI missing for 13 participants. Multivariate imputation by chained equations with baseline and discharge variables was used to impute missing values

readmission, leading to an apparent lack of association with the primary composite outcome (death or readmission). We hypothesize that for patients who died, having medication needs met was a marker of residual confounding by indication-sicker patients (i.e., those more likely to die) were more likely to have close attention paid to their discharge plans. These findings suggest that interventions purely targeted at assuring discharge medication needs are met may oversimplify the complex relationships among medication needs and patient outcomes.

Our data suggest that ARF survivors have high numbers of medication needs and more than half have at least one unmet medication need. This evidence is consistent with other observations about polypharmacy in this population [31, 32]. Notably, our study's secondary outcomes, at 3-month and 6-month follow-up, were consistent with prior cohorts noting high rates of psychological and cognitive disability after discharge [48, 49].

Our findings point toward the importance of additional research to design and test optimal interventions to improve recovery among acute respiratory failure survivors. These observations add to concerns raised about readmission-reduction programs intended to improve compliance with government metrics which led to worse patient outcomes overall [50-55] and emphasize the need for evidence from randomized controlled trials to support interventions and programs designed to improve post-discharge outcomes. 
Table 2 Baseline characteristics of enrolled patients divided by high versus low unmet medication needs

\begin{tabular}{|c|c|c|}
\hline Attribute & Unmet needs $<0.06, n=97$ & $\begin{array}{l}\text { Unmet } \\
\text { needs } \geq 0.06 \\
n=98\end{array}$ \\
\hline Age, years, median (IQR) & $55(41-66)$ & $55(44.2-63.8)$ \\
\hline Female sex, $n(\%)$ & $47(48.5 \%)$ & $57(58.2 \%)$ \\
\hline \multicolumn{3}{|l|}{ Race, $n(\%)$} \\
\hline Black & $34(35.1 \%)$ & $14(14.3 \%)$ \\
\hline Latinx & $2(2.1 \%)$ & $3(3.1 \%)$ \\
\hline Non-Hispanic White & $54(55.7 \%)$ & $75(76.5 \%)$ \\
\hline Other/multiple & $7(7.2 \%)$ & $6(6.1 \%)$ \\
\hline Body mass index $\left(\mathrm{kg} / \mathrm{m}^{2}\right)$, median (IQR) & $28.6(24.5-34.9)$ & $29.8(24.9-37.6)$ \\
\hline \multicolumn{3}{|l|}{ Respiratory support at enrollment, $n$ (\%) } \\
\hline Invasive mechanical ventilation & $72(74.2 \%)$ & $73(74.5 \%)$ \\
\hline Non-invasive mechanical ventilation & $7(7.2 \%)$ & $6(6.1 \%)$ \\
\hline High-flow nasal cannula & $18(18.6 \%)$ & $19(19.4 \%)$ \\
\hline Transferred from outside hospital, $n(\%)$ & $33(34.0 \%)$ & $42(42.9 \%)$ \\
\hline APACHE II, score, median (IQR) & $21(16-26)$ & $20(14-26)$ \\
\hline Current smoker, $n(\%)$ & $13(13.4 \%)$ & $18(18.4 \%)$ \\
\hline \multicolumn{3}{|l|}{ Insurance, $n(\%)$} \\
\hline Private and public & $18(18.6 \%)$ & $6(6.1 \%)$ \\
\hline Private & $42(43.3 \%)$ & $52(53.1 \%)$ \\
\hline Public & $33(34.0 \%)$ & $33(33.7 \%)$ \\
\hline None/other & $4(4.1 \%)$ & $7(7.1 \%)$ \\
\hline Acute respiratory distress syndrome, $n(\%)$ & $29(29.9 \%)$ & $32(32.7 \%)$ \\
\hline Clinically frailty scale, median (IQR) & $3(2-4)$ & $3(2-4)$ \\
\hline Multidimensional scale perceived social support, median (IQR) & $72(63-80)$ & $72(59.2-81)$ \\
\hline AUDIT score, median (IQR) & $0(0-2)$ & $1(0-2)$ \\
\hline Functional capacity index, median (IQR) & $2(1-3)$ & $2(1-3)$ \\
\hline Charlson comorbidity index, median (IQR) & $2(0-3)$ & $1(0-2.8)$ \\
\hline Resides at home before admission, $n(\%)$ & $93(95.9 \%)$ & $97(99.0 \%)$ \\
\hline Tested positive for COVID-19 during admission, $n(\%)$ & $14(14.4 \%)$ & $19(19.4 \%)$ \\
\hline Hospital length of stay, days, median (IQR) & $14(9-24)$ & $14(9.2-19)$ \\
\hline
\end{tabular}

Table 3 Primary outcome and constituents at 3 months, $n=195$

\begin{tabular}{|c|c|}
\hline Attribute & $\begin{array}{l}\text { Central } \\
\text { tendency } \\
\text { (dispersion) }\end{array}$ \\
\hline No death or readmission before 3 months, $n$ (\%) & $139(71.3 \%)$ \\
\hline Death or readmission before 3 months, $n(\%)$ & $56(28.7 \%)$ \\
\hline Time to primary outcome among those achieving primary outcome, days, median, (IQR) & $14(7-47)$ \\
\hline Death before 3 months, $n(\%)^{*}$ & $10(5.1 \%)$ \\
\hline Time to death among decedent, days, median (IQR) & $70.5(36.3-80)$ \\
\hline Hospital readmission before 3 months, $n$ (\%) & $52(26.7 \%)$ \\
\hline Time to readmission among those readmitted, days, median (IQR) & $12(6-32.75)$ \\
\hline
\end{tabular}

* Death before 3-month follow-up includes 6 participants that also were readmitted before the 3-month follow-up

Strengths of this study include its multicenter recruitment and robust follow-up rates $(\sim 95 \%)$. While this was not a randomized trial, we prospectively enrolled patients and employed appropriate statistical methods to estimate the average treatment effect. Limitations of the study include lack of randomization, lack of data 


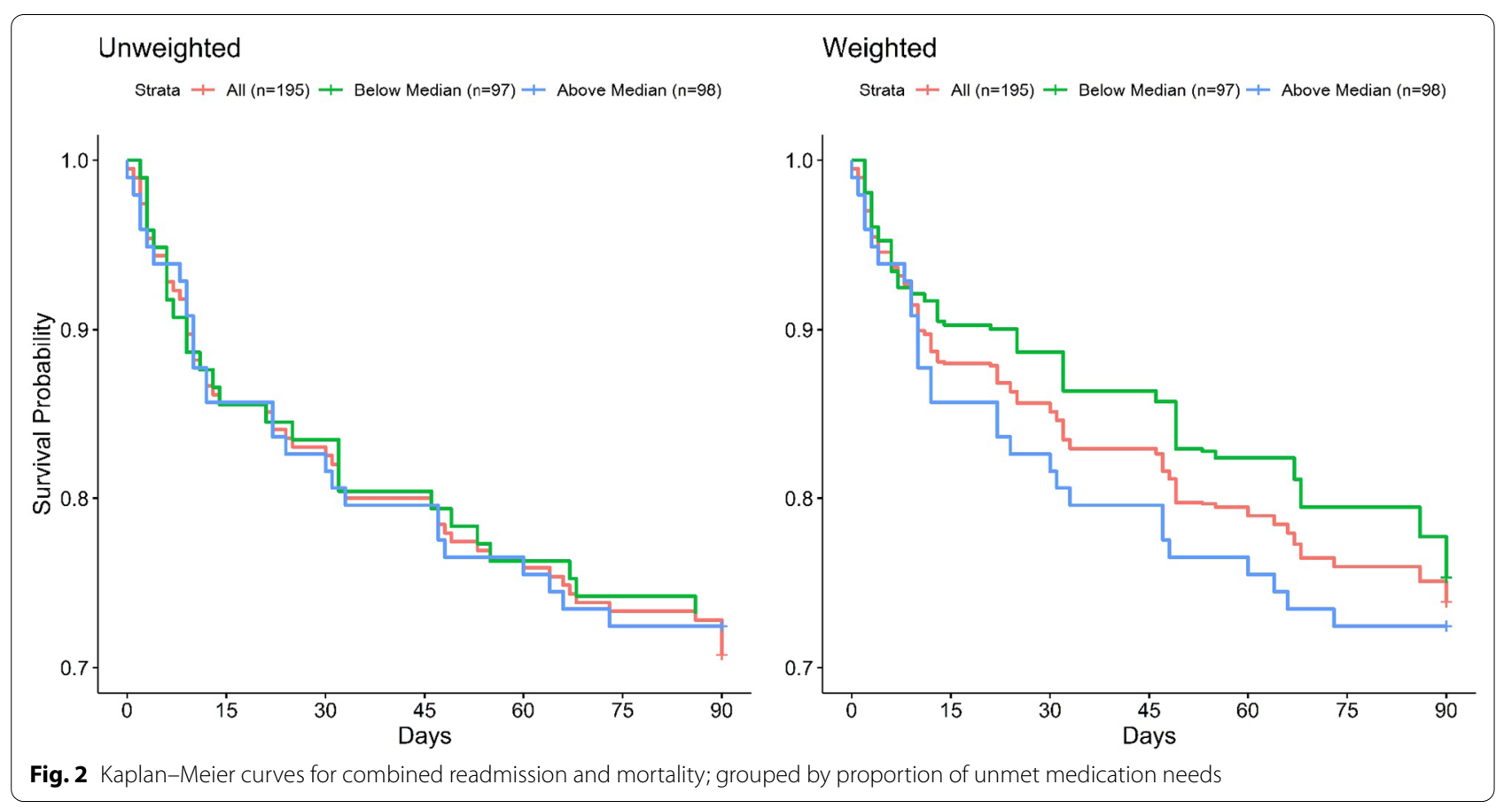

on medications patients were receiving at baseline, lack of specific data regarding the reasons that medication needs were unmet, and no in-depth data on palliative care interactions. We also acknowledge that small numbers of deaths severely limit the certainty of the association between unmet medication needs and mortality. Although study sites perform medication reconciliation routinely at hospital discharge, we did not perform a separate confirmation that the discharge medication plans were optimal.

The findings of the APICS-01 study will inform ongoing work to understand and test optimal approaches to supporting survivors of ARF. Substantial prior work has focused on ICU aftercare and recovery clinics, which attempt to provide and/or coordinate within one clinic, a range of healthcare-related services. Existing data on the effectiveness of these clinics have been mixed [35, 5658], perhaps reflecting the generally late (e.g., 3 months after discharge) initiation of such services. This model of support may miss an early window of vulnerability among ARF survivors, as suggested by a pilot randomized trial [47]. The pragmatic IMPACTS trial also suggested that a nurse navigator might improve outcomes among sepsis survivors [59]. The IMPACTS intervention included symptom monitoring, medication review, and targeted palliative care referrals. The present study provides confirmatory evidence that the early post-discharge period is an important target for interventions to improve outcomes for ARF survivors.

\section{Conclusion}

The APICS-01 study expands on prior retrospective, single-center or single-system observations via a multicenter, multisystem prospective cohort study, demonstrating that ARF survivors are at high risk for early post-discharge readmission and death. Moreover, ARF survivors, upon discharge to home, have many medication prescriptions and changes in medications. Distinct processes of unmet medication needs may separately drive early death and readmission. These findings are crucial to inform the design and evaluation of interventions to improve outcomes for this high-needs patient population.

\section{Supplementary Information}

The online version contains supplementary material available at https://doi. org/10.1186/s13054-021-03848-3.

Additional file 1: Online supplemental materials.

\section{Acknowledgements}

Elise Caraker; Sai Phani Sree Cherukuri; Naga Preethi Kadiri; Tejaswi Kalva; Mounica Koneru; Pooja Kota; Emma Maelian Lee; Mazin Ali Mahmoud; Albahi Malik; Roozbeh Nikooie; Darin Roberts; Sriharsha Singu; Parvaneh Vaziri; Katie Brown; Austin Daw; Mardee Merrill; Rilee Smith; Ellie Hirshberg; Jorie Butler; Benjamin Hoenig; Maria Karamourtopoulos; Margaret Hays; Rebecca Abel; Craig High; Emily Beck; Brent Armbruster; Darrin Applegate; Melissa Fergus; Naresh Kumar; Megan Roth; Susan Mogan (in memoriam); Rebecca Abel; Andrea De Souza Licht; Isabel Londono; Julia Larson; Krystal Capers; Andrew Toksoz-Exley; Julia Crane 


\section{Authors' contributions}

SMB, NA, DMN, SB, VBG, SB, VDD, ROH, JCJ, MMK, and CMS contributed to conceptualization. DG and TG performed statistical analysis. SMB and JCJ contributed to funding acquisition. SMB, DMN, and JCJ performed supervision. DMN and SMB performed writing - original draft. SMB, NA, DMN, SB, VBG, SB, VDD, ROH, AET, JCJ, MMK, and CMS performed writing-review and editing and approval. All authors read and approved the final manuscript.

\section{Funding}

Department of Defense. The U.S. Army Medical Research Acquisition Activity, 820 Chandler Street, Fort Detrick MD 21702-5014, is the awarding and administering acquisition office. This work was supported by The Assistant Secretary of Defense for Health Affairs endorsed by the Department of Defense through the FY17 PRMRP-Investigator-Initiated Research Award under Award No. W81XWH-18-1-0813. Opinions, interpretations, conclusions, and recommendations are those of the authors and are not necessarily endorsed by the Department of Defense.

\section{Availability of data and materials}

In order to protect patient privacy and comply with relevant regulations, identified data are unavailable. Requests for deidentified data from qualified researchers with appropriate ethics board approvals and relevant data use agreements will be processed by the Intermountain Office of Research, officeofresearch@imail.org.

\section{Declarations}

\section{Ethical approval and consent to participate}

Ethical approval and consent to participate were obtained from relevant ethics boards and all participants or their legally authorized representatives. Research involving human participants was performed according to appropriate ethical standards.

\section{Consent for publication}

Not applicable.

\section{Competing interests}

The authors have declared that no competing interests exist.

\section{Author details}

${ }^{1}$ Pulmonary and Critical Care Medicine, Intermountain Medical Center, Salt Lake City, UT, USA. ${ }^{2}$ Pulmonary and Critical Care Medicine, University of Utah, Salt Lake City, UT, USA. ${ }^{3}$ Center for Humanizing Critical Care, Intermountain Medical Center, Salt Lake City, UT, USA. ${ }^{4}$ Outcomes After Critical IIIness and Surgery (OACIS) Group and Pulmonary and Critical Care Medicine, School of Medicine, Johns Hopkins University, Baltimore, MD, USA. ${ }^{5}$ Department of Internal Medicine, Yale School of Medicine, New Haven, CT, USA. ${ }^{6}$ Beth Israel Deaconess Medical Center, Boston, MA, USA. ${ }^{7}$ Biostatistics and Epidemiology, University of Utah, Salt Lake City, UT, USA. ${ }^{8}$ Psychology Department and Neuroscience Center, Brigham Young University, Provo, UT, USA. ${ }^{9}$ Salt Lake City Veterans Administration, Salt Lake City, UT, USA. ${ }^{10}$ Vanderbilt University Medical Center, Nashville, TN, USA. ${ }^{11}$ Shock Trauma ICU, Intermountain Medical Center, 5121 S. Cottonwood Street, Murray, UT 84107, USA.

Received: 6 October 2021 Accepted: 29 November 2021

Published online: 07 January 2022

\section{References}

1. Zimmerman JE, Kramer AA, Knaus WA. Changes in hospital mortality for United States intensive care unit admissions from 1988 to 2012. Crit Care (Lond Engl). 2013;17:R81.

2. Phua J, Badia JR, Adhikari NKJ, Friedrich JO, Fowler RA, Singh JM, Scales DC, Stather DR, Li A, Jones A, Gattas DJ, Hallett D, Tomlinson G, Stewart TE, Ferguson ND. Has mortality from acute respiratory distress syndrome decreased over time?: A systematic review. Am J Respir Crit Care Med. 2009;179:220-7.

3. Zambon M, Vincent J-L. Mortality rates for patients with acute lung injury/ARDS have decreased over time. Chest. 2008;133:1120-7.
4. Erickson SE, Martin GS, Davis JL, Matthay MA, Eisner MD, Network NNA. Recent trends in acute lung injury mortality: 1996-2005. Crit Care Med. 2009;37:1574-9.

5. Spragg RG, Bernard GR, Checkley W, Curtis JR, Gajic O, Guyatt G, Hall J, Israel E, Jain M, Needham DM, Randolph AG, Rubenfeld GD, Schoenfeld D, Thompson BT, Ware LB, Young D, Harabin AL. Beyond mortality: future clinical research in acute lung injury. Am J Respir Crit Care Med. 2010;181:1121-7

6. Hauschildt KE, Seigworth C, Kamphuis LA, Hough CL, Moss M, McPeake JM, Iwashyna TJ. Financial toxicity after acute respiratory distress syndrome: a national qualitative cohort study. Crit Care Med. 2020:48:1103-10

7. Hopkins RO, Weaver LK, Pope D, Orme JF, Bigler ED, Larson-Lohr V. Neuropsychological sequelae and impaired health status in survivors of severe acute respiratory distress syndrome. Am J Respir Crit Care Med. 1999:160:50-6.

8. Hopkins RO, Weaver LK, Chan KJ, Orme JF. Quality of life, emotional, and cognitive function following acute respiratory distress syndrome. J Int Neuropsychol Soc JINS. 2004;10:1005-17.

9. Needham DM, Dinglas VD, Bienvenu OJ, Colantuoni E, Wozniak AW, Rice TW, Hopkins RO, Network NNA. One year outcomes in patients with acute lung injury randomised to initial trophic or full enteral feeding: prospective follow-up of EDEN randomised trial. BMJ (Clin Res Ed). 2013;346:f1532.

10. Needham DM, Dinglas VD, Morris PE, Jackson JC, Hough CL, MendezTellez PA, Wozniak AW, Colantuoni E, Ely EW, Rice TW, Hopkins RO, Network NNA. Physical and cognitive performance of patients with acute lung injury 1 year after initial trophic versus full enteral feeding. EDEN trial follow-up. Am J Respir Crit Care Med. 2013;188:567-76.

11. Dowdy DW, Eid MP, Dennison CR, Mendez-Tellez PA, Herridge MS, Guallar E, Pronovost PJ, Needham DM. Quality of life after acute respiratory distress syndrome: a meta-analysis. Intensive Care Med. 2006;32:1115-24.

12. Hopkins RO, Weaver LK, Collingridge D, Parkinson RB, Chan KJ, Orme JF. Two-year cognitive, emotional, and quality-of-life outcomes in acute respiratory distress syndrome. Am J Respir Crit Care Med. 2005;171:340-7.

13. Pandharipande PP, Girard TD, Jackson JC, Morandi A, Thompson JL, Pun BT, Brummel NE, Hughes CG, Vasilevskis EE, Shintani AK, Moons KG, Geevarghese SK, Canonico A, Hopkins RO, Bernard GR, Dittus RS, Ely EW. Long-term cognitive impairment after critical illness. N Engl J Med. 2013;369:1306-16.

14. Kamdar BB, Huang M, Dinglas VD, Colantuoni E, von Wachter TM, Hopkins RO, Needham DM, National Heart L, Blood Institute Acute Respiratory Distress Syndrome N. Joblessness and lost earnings after acute respiratory distress syndrome in a 1-year national multicenter study. Am J Respir Crit Care Med. 2017;196:1012-20.

15. Kamdar BB, Sepulveda KA, Chong A, Lord RK, Dinglas VD, Mendez-Tellez PA, Shanholtz C, Colantuoni E, von Wachter TM, Pronovost PJ, Needham DM. Return to work and lost earnings after acute respiratory distress syndrome: a 5-year prospective, longitudinal study of long-term survivors. Thorax. 2018;73:125-33.

16. Kamdar BB, Suri R, Suchyta MR, Digrande KF, Sherwood KD, Colantuoni E, Dinglas VD, Needham DM, Hopkins RO. Return to work after critical illness: a systematic review and meta-analysis. Thorax. 2019;75:17-27.

17. Heyland DK, Groll D, Caeser M. Survivors of acute respiratory distress syndrome: relationship between pulmonary dysfunction and long-term health-related quality of life. Crit Care Med. 2005;33:1549-56.

18. Hopkins RO, Herridge MS. Quality of life, emotional abnormalities, and cognitive dysfunction in survivors of acute lung injury/acute respiratory distress syndrome. Clin Chest Med. 2006;27:679-89.

19. Schelling G, Stoll C, Vogelmeier C, Hummel T, Behr J, Kapfhammer HP, Rothenhäusler HB, Haller M, Durst K, Krauseneck T, Briegel J. Pulmonary function and health-related quality of life in a sample of long-term survivors of the acute respiratory distress syndrome. Intensive Care Med. 2000;26:1304-11.

20. Ruhl AP, Huang M, Colantuoni E, Karmarkar T, Dinglas VD, Hopkins RO, Needham DM, With the National Institutes of Health NHL, Blood Institute Acute Respiratory Distress Syndrome N. Healthcare utilization and costs in ARDS survivors: a 1-year longitudinal national US multicenter study. Intensive Care Med. 2017:43:980-91.

21. Taylor SP, Chou S-H, Figueroa Sierra M, Shuman TP, McWilliams AD, Taylor BT, Russo M, Evans SL, Rossman W, Murphy S, Cunningham K, 
Kowalkowski MA. Association between adherence to recommended care and outcomes for adult survivors of sepsis. Ann Am Thorac Soc. 2019;17:89-97.

22. Prescott HC, Langa KM, Iwashyna TJ. Readmission diagnoses after hospitalization for severe sepsis and other acute medical conditions. JAMA. 2015;313:1055-7.

23. Prescott HC, Langa KM, Liu V, Escobar GJ, Iwashyna TJ. Increased 1-year healthcare use in survivors of severe sepsis. Am J Respir Crit Care Med. 2014;190:62-9.

24. Liu V, Lei X, Prescott HC, Kipnis P, Iwashyna TJ, Escobar GJ. Hospital readmission and healthcare utilization following sepsis in community settings. J Hosp Med. 2014;9:502-7.

25. Hernandez AF, Greiner MA, Fonarow GC, Hammill BG, Heidenreich PA, Yancy CW, Peterson ED, Curtis LH. Relationship between early physician follow-up and 30-day readmission among medicare beneficiaries hospitalized for heart failure. JAMA. 2010;303:1716-22.

26. Jencks SF, Williams MV, Coleman EA. Rehospitalizations among patients in the medicare fee-for-service program. N Engl J Med. 2009;360:1418-28.

27. Moore C, McGinn T, Halm E. Tying up loose ends: discharging patients with unresolved medical issues. Arch Intern Med. 2007;167:1305-11.

28. Feltner C, Jones CD, Cené CW, Zheng Z-J, Sueta CA, Coker-Schwimmer EJL, Arvanitis M, Lohr KN, Middleton JC, Jonas DE. Transitional care interventions to prevent readmissions for persons with heart failure: a systematic review and meta-analysis. Ann Intern Med. 2014;160:774-84.

29. Morandi A, Vasilevskis E, Pandharipande PP, Girard TD, Solberg LM, Neal EB, Koestner T, Torres RE, Thompson JL, Shintani AK, Han JH, Schnelle JF, Fick DM, Ely EW, Kripalani S. Inappropriate medication prescriptions in elderly adults surviving an intensive care unit hospitalization. J Am Geriatr Soc. 2013;61:1128-34

30. Sevin CM, Bloom SL, Jackson JC, Wang L, Ely EW, Stollings JL. Comprehensive care of ICU survivors: development and implementation of an ICU recovery center. J Crit Care. 2018:46:141-8.

31. Stollings JL, Bloom SL, Huggins EL, Grayson SL, Jackson JC, Sevin CM. Medication management to ameliorate post-intensive care syndrome. AACN Adv Crit Care. 2016;27:133-40.

32. Stollings JL, Bloom SL, Wang L, Ely EW, Jackson JC, Sevin CM. Critical care pharmacists and medication management in an ICU recovery center. Ann Pharmacother. 2018:52:713-23.

33. Jackson J, et al. Addressing post-intensive care syndrome (APICS-01) (MHSRS-19-00923). In: 2019 Military health sciences research symposium. 2019.

34. Brown SM, et al. Combating long-term respiratory consequences of airborne hazards on the battlefield - the APICS-01 study annual update (MHSRS-20-00233). In: 2020 Military health sciences research symposium. 2020.

35. Brown SM, Bose S, Banner-Goodspeed V, Beesley SJ, Dinglas VD, Hopkins RO, Jackson JC, Mir-Kasimov M, Needham DM, Sevin CM. Addressing Post intensive care syndrome 01 study t. Approaches to addressing postintensive care syndrome among intensive care unit survivors. A narrative review. Ann Am Thorac Soc. 2019;16:947-56.

36. Akhlaghi N, Needham DM, Bose S, Banner-Goodspeed VM, Beesley SJ, Dinglas VD, Groat D, Greene T, Hopkins RO, Jackson J, Mir-Kasimov M, Sevin CM, Wilson E, Brown SM. Evaluating the association between unmet healthcare needs and subsequent clinical outcomes: protocol for the addressing post-intensive care syndrome-01 (APICS-01) multicentre cohort study. BMJ Open. 2020;10:e040830.

37. Jorm AF. A short form of the informant questionnaire on cognitive decline in the elderly (IQCODE): development and cross-validation. Psychol Med. 1994;24:145-53.

38. Lin JS, O'Connor E, Rossom RC, Perdue LA, Eckstrom E. Screening for cognitive impairment in older adults: a systematic review for the U.S. Preventive services task force. Ann Intern Med. 2013;159:601-12.

39. Needham DM, Sepulveda KA, Dinglas VD, Chessare CM, Friedman LA, Bingham CO 3rd, Turnbull AE. Core outcome measures for clinical research in acute respiratory failure survivors. An international modified Delphi consensus study. Am J Respir Crit Care Med. 2017;196:1122-30.

40. Turnbull AE, Sepulveda KA, Dinglas VD, Chessare CM, Bingham CO 3rd, Needham DM. Core domains for clinical research in acute respiratory failure survivors: an international modified Delphi consensus study. Crit Care Med. 2017:45:1001-10.
41. Robinson KA, Dinglas VD, Sukrithan V, Yalamanchilli R, Mendez-Tellez PA, Dennison-Himmelfarb C, Needham DM. Updated systematic review identifies substantial number of retention strategies: using more strategies retains more study participants. J Clin Epidemiol. 2015;68:1481-7.

42. Haines KJ, Berney S, Warrillow S, Denehy L. Long-term recovery following critical illness in an Australian cohort. J Intensive Care. 2018;6:8.

43. Dinglas VD, Huang M, Sepulveda KA, Pinedo M, Hopkins RO, Colantuoni E, Needham DM, Network NNA. Personalized contact strategies and predictors of time to survey completion: analysis of two sequential randomized trials. BMC Med Res Methodol. 2015;15:5.

44. Tansey CM, Matté AL, Needham D, Herridge MS. Review of retention strategies in longitudinal studies and application to follow-up of ICU survivors. Intensive Care Med. 2007:33:2051-7.

45. Coday M, Boutin-Foster C, Goldman Sher T, Tennant J, Greaney ML, Saunders SD, Somes GW. Strategies for retaining study participants in behavioral intervention trials: retention experiences of the $\mathrm{NIH}$ behavior change consortium. Ann Behav Med. 2005;29(Suppl):55-65.

46. Imai K, Ratkovic M. Covariate balancing propensity score. J R Stat Soc Ser B (Stat Methodol). 2014;76:243-63.

47. Bloom SL, Stollings JL, Kirkpatrick O, Wang L, Byrne DW, Sevin CM, Semler MW. Randomized clinical trial of an ICU recovery pilot program for survivors of critical illness. Crit Care Med. 2019;47:1337-45.

48. Huang M, Parker AM, Bienvenu OJ, Dinglas VD, Colantuoni E, Hopkins RO, Needham DM. Psychiatric symptoms in acute respiratory distress syndrome survivors: a 1-year national multicenter study. Crit Care Med. 2016:44:954-65.

49. Needham DM, Colantuoni E, Dinglas VD, Hough CL, Wozniak AW, Jackson JC, Morris PE, Mendez-Tellez PA, Ely EW, Hopkins RO. Rosuvastatin versus placebo for delirium in intensive care and subsequent cognitive impairment in patients with sepsis-associated acute respiratory distress syndrome: an ancillary study to a randomised controlled trial. Lancet Respir Med. 2016;4:203-12.

50. Gu Q, Koenig L, Faerberg J, Steinberg CR, Vaz C, Wheatley MP. The medicare hospital readmissions reduction program: potential unintended consequences for hospitals serving vulnerable populations. Health Serv Res. 2014;49:818-37.

51. Chen M, Grabowski DC. Hospital readmissions reduction program: intended and unintended effects. Med Care Res Rev. 2019;76:643-60.

52. Fonarow GC. Unintended harm associated with the hospital readmissions reduction program. JAMA. 2018;320:2539-41.

53. Bhalla R, Kalkut G. Could medicare readmission policy exacerbate health care system inequity? Am Coll Physicians. 2010;152:114-7.

54. Gupta A, Allen LA, Bhatt DL, Cox M, DeVore AD, Heidenreich PA, Hernandez AF, Peterson ED, Matsouaka RA, Yancy CW. Association of the hospital readmissions reduction program implementation with readmission and mortality outcomes in heart failure. JAMA Cardiol. 2018;3:44-53.

55. Wadhera RK, Joynt Maddox KE, Wasfy JH, Haneuse S, Shen C, Yeh RW. Association of the hospital readmissions reduction program with mortality among medicare beneficiaries hospitalized for heart failure, acute myocardial infarction, and pneumonia. JAMA. 2018;320:2542-52.

56. Elliott D, McKinley S, Alison J, Aitken LM, King M, Leslie GD, Kenny P, Taylor P, Foley R, Burmeister E. Health-related quality of life and physical recovery after a critical illness: a multi-centre randomised controlled trial of a home-based physical rehabilitation program. Crit Care (Lond Engl). 2011;15:R142.

57. Cuthbertson BH, Rattray J, Campbell MK, Gager M, Roughton S, Smith A, Hull A, Breeman S, Norrie J, Jenkinson D, Hernández R, Johnston M, Wilson E, Waldmann C. The PRaCTICaL study of nurse led, intensive care follow-up programmes for improving long term outcomes from critical illness: a pragmatic randomised controlled trial. BMJ (Clin Res Ed). 2009;339:b3723.

58. Jensen JF, Egerod I, Bestle MH, Christensen DF, Elklit A, Hansen RL, Knudsen $\mathrm{H}$, Grode LB, Overgaard D. A recovery program to improve quality of life, sense of coherence and psychological health in ICU survivors: a multicenter randomized controlled trial, the RAPIT study. Intensive Care Med. 2016;42:1733-43.

59. Taylor SP, Murphy S, Rios A, McWilliams A, McCurdy L, Chou SH, Hetherington T, Rossman W, Russo M, Gibbs M, Kowalkowski MA. Effect of a multicomponent sepsis transition and recovery program on mortality and readmissions after sepsis: the improving morbidity during post-acute 
care transitions for sepsis randomized clinical trial. Crit Care Med. 2021. https://doi.org/10.1097/CCM.0000000000005300.

\section{Publisher's Note}

Springer Nature remains neutral with regard to jurisdictional claims in published maps and institutional affiliations.

- fast, convenient online submission

- thorough peer review by experienced researchers in your field

- rapid publication on acceptance

- support for research data, including large and complex data types

- gold Open Access which fosters wider collaboration and increased citations

- maximum visibility for your research: over $100 \mathrm{M}$ website views per year

At BMC, research is always in progress.

Learn more biomedcentral.com/submissions 